\title{
Examination of PCDD/F Formation in Thermal Systems Using Simple Mathematical Models
}

\author{
Brian R. Stanmore *
}

Mclvor Park Court, Junortoun, Victoria 3551, Australia; E-Mail: $\underline{\text { b.stanmore@uq.edu.au }}$

* Correspondence: Brian R. Stanmore; E-Mail: b.stanmore@uq.edu.au

Academic Editor: M. Glória Pereira

Special Issue: Persistent Organic Pollutants

Adv Environ Eng Res

2021, volume 2, issue 2

doi:10.21926/aeer.2102013
Received: March 01, 2021

Accepted: May 31, 2021

Published: June 07,2021

\begin{abstract}
A set of empirical models which accounts for the formation of gas phase polychlorinated dibenzo-p-dioxins and furans (PCDD and PCDF), and solid phase PCDD/F by the de novo mechanism is described. In each case, competing formation and destruction reactions are considered to operate. The effect of the time-temperature history on their formation is then examined. At high temperatures, steady-state is reached in fractions of a second, resulting in the observed low product concentrations. Rapid cooling as found in furnaces produces higher $\mathrm{PCDD} / \mathrm{F}$ nett formation rates than slower cooling over the same temperature range, but with less overall yield. In addition, a cooling process will result in more PCDD/F production than heating at the same rate. Thus the conventionally-regarded temperature "windows" for formation are misleading, as in practical conditions PCDD/F are produced at higher temperatures. Simulations carried out of a pilot scale municipal solid waste (MSW) incinerator, a commercial fluidised bed boiler burning wood as a fuel, and of the laboratory scale thermal "annealing" of particulates taken from iron ore sintering off-gases illustrate the effects. There is sufficient promise in the approach to suggest that better characterisation of particulates will lead to acceptable predictions.
\end{abstract}

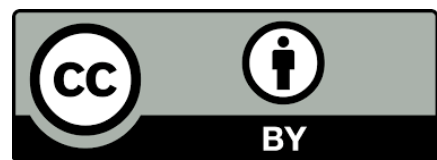

(C) 2021 by the author. This is an open access article distributed under the conditions of the Creative Commons by Attribution License, which permits unrestricted use, distribution, and reproduction in any medium or format, provided the original work is correctly cited. 


\section{Keywords}

Dioxins; PCDD/F; formation; mathematical model

\section{Introduction}

The question of dioxin emissions to the atmosphere from combustion processes was a burning question (!) in the early years of this century, and the technical literature contains a plethora of submissions. This interest has been displaced recently by other compounds, such that the last review of the chemistry involved appears to be Altarawneh et al [1]. Nevertheless, the material is a regulated emission, and any advance in estimating its formation in thermal processes would be of use to practitioners in the field.

The most common process studied is municipal solid waste MSW combustion, which is widespread in application and contributes significantly to local emission loads. The detection of polychlorinated dibenzo- $p$-dioxins and furans PCDD/F in MSW flue-gases in the 1980s sparked a flurry of research, which identified its generation from polyaromatic hydrocarbons (PAH) and chlorinated precursors in the gas phase, and formation on carbonaceous particulates. The copper present in MSW was found to be an excellent promoter/catalyst for the latter reaction.

From the observed isomer patterns, it is clear that a combination of chlorination and dechlorination reactions is the dominant formation mechanism for PCDF, whereas condensation reactions of phenolic precursors appear to be responsible for PCDD formation [2]. The complexity of the processes involved means that a wide range of variables must be considered. Those chosen as significant by some authors are neglected by others. Many of the models contain empiricisms which have been adopted in order to fit simplified expressions to a complex network of compounds and reactions.

Initial homogeneous gas-phase investigations were begun by Shaub and Tsang [3, 4], with the governing rate given by an expression of the form $k=275(T / 973) 1 / 2 \exp (-11,500 / R T) s^{-1}$. This was followed up by a routine to estimate their formation from chlorinated gas-phase precursors [5]. Subsequently, the realisation that the majority of PCDD/F type material is present on the MSW flyash led to concentration on that pathway, and the de novo process involving elemental carbon was identified. A much-quoted experimental investigation into the gas phase system was carried out by [6], and there was evidence that copper-containing particle act as catalyst in gas-phase reactions [7]. Work on PCDD/F formation still appears at irregular intervals.

The standard method of establishing rates of formation for the de novo process is the isothermal "annealing' experiment, in which a small sample of the particulate of interest is exposed to elevated temperatures under an oxidising gas stream for a set period. The required carbon and chlorine may be inherent or externally added, as well as copper. A variation of this technique used to study precursor formation involves the addition of chlorophenols and/or chlorobenzenes to the gas such that they are adsorbed and react on the surface e.g. Milligan and Altwicker [8]. As will be shown later, this technique can give misleading results in non-isothermal conditions.

A number of kinetic models of varying scope describing the rate of formation of PCDD/F in MSW combustion systems appeared in the period 1990-2005. The work of Shaub and Tsang was incorporated into a kinetic model involving flyash by Penner et al [9]. Gas-phase precursors 
adsorb/desorb at the ash surface while reacting to form dioxins. Altwicker [10] also concentrated on a precursor route by incorporating a Freundlich adsorption isotherm with a LangmuirHinshelwood reaction sequence. His de novo model consists of reaction, desorption, dechlorination, and decomposition steps with assumed Arrhenius pre-exponentials and activation energies.

In gas-phase systems, Babushok and Tsang [11] focus on the production of free chlorine with subsequent mixing leading to chlorine atoms as the main reactive radicals. High concentrations of chlorinated phenoxy radicals can be formed, giving polychlorinated phenol, polychlorinated phenoxy radicals, polychlorinated 2-phenoxyphenols, and PCDD. CHEMKIN modelling was employed by Katchatryan et al [12] with a system of 45 reactions to account for the major features in the homogeneous formation of dioxins from the oxidation of 2,4,6-trichlorophenol.

Gullett et al [13] employed a stepwise regression analysis to determine the predictive parameters for four models of PCDD, PCDF, the total of PCDD and PCDF yield, and the partitioning between PCDD and total yield on MSW ash passing through a laboratory drop-tube furnace. The variables, which included temperature, quench rate, residence time, oxygen concentration, and chlorine speciation produced a reliable predictive outcome.

The early attempts to globally describe waste-to-energy plants burning MSW include an empirically-derived, Gaussian model for a bell-shape reaction rate profile with temperature [14], and a neural network approach [15]. The dynamics of furnace processes were modelled under PSR conditions (Perfectly Stirred Reactor) by Chagger et al [16], who demonstrated that the formation of chlorinated compounds during the quenching process was thermodynamically favoured.

Huang and Buekens [17] set up a kinetic model for PCDD formation from gaseous chlorophenols on flyash using a Langmuir-Hinshelwood scheme which included adsorption, desorption, decomposition and reaction stages. Kinetic parameters for all four processes were derived from experimental data. At high chlorophenol concentrations, the rate is first order, but reverts to second order at low values. They complemented this with a similar model for the de novo system [18], where only three steps are incorporated, namely formation from carbon during its gasification, dioxin/furan devolatilization from the solid and its thermal destruction. The rate is first order with respect to carbon and half order with oxygen concentration.

A similar approach for the de novo process by Mätzing [19] also links the rate to carbon combustion, modified by the oxygen and moisture content of the gases. The method of Gan et al [20] also focusses on the de novo route, which is assumed to dominate the generation of PCDD/F in MSW furnaces. Temperature is tracked with a computational fluid dynamics CFD model, while the carbon and copper contents of the solid and oxygen in the gas phase were the variables employed. A more fundamental model by Grandesso et al [21] is limited to the specific conditions of high carbon particulates.

This author constructed the simple approach outlined below [22-25] in an attempt to provide a method of predicting the likely PCDD/F emissions from operating plants c.f. Shin et al [14]. Although the results gave realistic levels of dioxins in the systems tested, some aspects are now recognised as inadequate.

As research proceeds and the formation processes are better understood, empiricisms can be refined or removed. In contrast, rather than providing a mathematical description of the various routes of formation in thermal processes, the aim of the present paper is to offer a simplified overall method of estimating emissions. The method, which is directed towards plant operators, is purely empirical, but has been developed from observations of PCDD/F formation. Calculation of PCDD/F 
emissions in a thermal system therefore requires the numerical integration with time of only two equations, so that the execution is suitable for EXCEL or another simple spreadsheet.

The bulk of the models apply to MSW incinerators and are thus of limited application. The approach previously developed by the author $[22,25]$ covers both gas and solid phase formation from precursors and the de novo reaction, and attempts to cover a broader range of thermal processes. This set of models has now been further refined and consolidated, and is applied here under different combustion situations.

\section{Description of the Model}

The present approach proposes that the net quantity of PCDD/F present is determined by a competition between formation and destruction reactions. In reality a complex network of reactions is present e.g. lino et al [26], including formation, further chlorination, desorption, dechlorination and decomposition. As mass transfer effects are unlikely [27], all the equations employed are of Arrhenius form, as given by Eq. (1):

$$
\frac{d_{\text {Product }}}{d t}=A \exp \left[-\frac{E}{T}\right]\left[X_{1}\right]^{a}\left[X_{2}\right]^{b}\left[X_{3}\right]^{c}
$$

Here $A$ is the pre-exponential factor, $E$ is a form of activation energy and $X_{1}, X_{2}$ and $X_{3}$ are the concentrations of reactants. A summary of the values used for the different reactions outlined below is given in Table 1.

Table 1 Values used in Equation (1).

\begin{tabular}{|c|c|c|c|c|c|c|c|}
\hline$E q^{\prime} n$ & Product & A & $\mathbf{E}$ & $x_{1}$ & $x_{2}$ & $X_{3}$ & Detail \\
\hline & $*$ & $s^{-1}$ & K & $*$ & $*$ & $*$ & \\
\hline \multicolumn{8}{|c|}{ Gas phase } \\
\hline $1 \mathrm{~A}$ & PCCD $^{1}$ & $8.5 \times 10^{5}$ & 12,500 & $\mathrm{PCP}{ }^{3}$ & - & & Formation \\
\hline \multirow[t]{2}{*}{$1 B$} & PCDF $^{1}$ & $3 \times 10^{6}$ & 12,500 & $\mathrm{PCP}{ }^{3}$ & PCBz ${ }^{3}$ & - & Formation \\
\hline & - & & & $a=0.5$ & $b=0.5$ & & \\
\hline $1 C$ & & $5 \times 10^{14}$ & 30,000 & $\mathrm{PCDD} / \mathrm{F}^{3}$ & - & & Destruction \\
\hline \multicolumn{8}{|c|}{ Precursor } \\
\hline $1 D$ & $\mathrm{PCDD}^{2}$ & 13 & 10,500 & $\mathrm{PCP} 3$ & - & & Formation \\
\hline $1 \mathrm{E}$ & & $2.5 \times 10^{15}$ & 25,000 & $\mathrm{PCDD}^{4}$ & - & - & Destruction \\
\hline \multicolumn{8}{|c|}{ De novo } \\
\hline \multirow[t]{2}{*}{$1 \mathrm{~F}$} & $\mathrm{PCDD} / \mathrm{F}^{2}$ & $3.0 \times 10^{5}$ & 12,000 & $C^{5}$ & $\mathrm{Cl}^{5}$ & $\mathrm{O}_{2}{ }^{5}$ & Formation \\
\hline & & & & $a=1$ & $b=1$ & $c=0.6$ & \\
\hline $1 G$ & - & $2.8 \times 10^{18}$ & 30,000 & $\mathrm{PCDD} / \mathrm{F}^{4}$ & - & - & Destruction \\
\hline
\end{tabular}

* Units: 1 . nmol m $\mathrm{m}^{-3} \mathrm{~s}^{-1}$; 2 nmol m $\mathrm{m}^{-2} \mathrm{~s}^{-1} ; 3 . \mu \mathrm{mol} \mathrm{m} \mathrm{m}^{-3} ; 4 . \mu \mathrm{mol} \mathrm{m}{ }^{-2} ; 5$. Mass $\%$

The equations were integrated numerically. The increase in concentration of PCDD over time $\Delta t$ at any temperature due to the formation reaction is

$$
\Delta \mathrm{Ci}=\mathrm{r}_{\mathrm{f}}\left[\mathrm{C}_{\text {reactant }(\mathrm{s})}\right] \Delta \mathrm{t} \mathrm{nmol} \mathrm{m}^{-3} \text { or } \mathrm{nmol} \mathrm{m}^{-2}
$$


where $C$ is concentration and $r_{f}$ is the relative Arrhenius expression (see Table 1):

$$
r_{f}=A_{f} \exp \left(-E_{f} / T\right) s^{-1}
$$

The new concentration or nett value as a result of the $\mathrm{i}_{\text {th }}$ iteration is

$$
\mathrm{C}_{\mathrm{i}+1}=\left(\mathrm{C}_{\mathrm{i}}+\Delta \mathrm{C}_{\mathrm{i}}\right)\left(1-\mathrm{r}_{\mathrm{d}} \Delta \mathrm{t}\right) \quad \mathrm{nmol} \mathrm{m}^{-3} \text { or nmol m}{ }^{-2}
$$

where $r_{d}$ is the expression for the destruction reaction similar to $r_{f}$ (Table 1).

The result is sensitive to integration step size $\Delta t$ at higher temperatures, where the formation and destruction rates are almost equal and changing rapidly. From the expression for $\mathrm{C}_{i+1}$, the first formation step can only occur when $\Delta t<1 / r_{d}$. Therefore, using microsecond increments, nett formation could result at any temperature, including those above what is usually considered active (e.g. $1400 \mathrm{~K}$ for dioxins), but the nett amount of PCDD/F formed plateaus quickly, and is negligible. Decreasing the step size at elevated temperatures to the order of one millisecond avoids any instability. At lower temperatures a step size up to 0.1 seconds can be satisfactory. Nett values which were negative were replaced by zero.

\subsection{Gas Phase PCDD/F}

The PCDD/Fs in any original fuel are destroyed in combustion [28], so that the material found in flue gases has resulted from post-combustion processes. It is assumed that PCDD forms from multichlorinated phenols (PCP) of any degree of chlorination other than mono [29], and PCDF from $\mathrm{PCP}$ and polychlorinated benzenes (PCBz). This is a gross simplification, as many pathways have been identified e.g. Oh et al [30]. They observe that the pathways to PCDD and PCDF generally differ, with the dioxins formed by condensation of chlorophenols, while the furans tend to be formed via PCBzs, PAHs, and chlorinated naphthalenes. On flyash, any PCBz formed contributes to PCDF, but not to PCDD [31]. Furans result directly from preformed biphenyl structures [32]. The approach outlined here relies on the assumption that the amount precursor materials of all kinds will be comparable i.e. high concentration of PCPs will be accompanied by high amounts of the alternatives.

PCDD is assumed to form according to Equation (1A), which is first order in respect to PCP [29, 33]. The competing destruction reaction is described by another Arrhenius equation with a higher activation energy, Equation (1C), so that as temperature rises, this reaction comes to dominate the formation reactions. Collina et al [34] report that the decomposition reaction is of the first order with respect to the reactant adsorbed physically, while the dechlorination reaction involved firstorder series reactions.

The two formation reactions and the destruction reaction are numerically integrated simultaneously over the time period during which the gases are in the appropriate temperature regime, while continually adjusting the temperature. The routine assumes that the concentrations of chlorophenols and chlorobenzenes remain unchanged during this period.

A process for determining Arrhenius parameters is to consider the temperature extremes, which is adequate given the assumptions involved. Activation energies for formation are controlling at lower temperatures where the destruction reactions are negligible, and conversely the destruction reaction dominates at higher temperatures. The pre-exponential factors can then be fitted by iteration. The experimental data from Sidhu et al [6], where 2,3,6 trichlorophenol in air was passed 
through a heated quartz reactor with a 2 second residence time was used. From this data, it was estimated that respective values of $E$ should be $104 \mathrm{~kJ} \mathrm{~mol}^{-1}$ and $250 \mathrm{~kJ} \mathrm{~mol}^{-1}$. The values of $A$ were then fitted, see Table 1.

PCDF on the other hand appears to be formed via a variety of pathways, and is better fitted by a reaction involving both $\mathrm{PCP}$ and polychlorinated benzenes ( $\mathrm{PCBz})$. The activation energy found for PCDD was retained, whereas the order of reaction for each was set at 0.5 to preserve parity between the two species, Equation (1B). Some average concentrations of PCP / PCBz in the flue gases of two MSW furnaces are roughly identical [30] at $13 / 18$ and $36 / 39 \mu \mathrm{g} \mathrm{Sm}^{-3}$. Other values are $20 / 3.1 \mu \mathrm{g}$ $\mathrm{Sm}^{-3}$ respectively [35], or $1.2 / 2.0 \mu \mathrm{g} \mathrm{Sm}{ }^{-3}$ [36].

Although in many combustion systems the concentrations of PCP and PCBz in the fluegas are unknown, estimates can be made by reconciling experimental data. The concentrations of the chlorobenzenes can be of the same order as those of chlorophenols [30], or somewhat lower [35]. The PCPs and PCBzs formed from MSW are concentrated in the $\mathrm{Cl}_{3}$ congeners $[2,28]$, such that their mean molecular masses were taken as 200 and 180 respectively.

During the combustion of MSW under controlled conditions, the mass of PCP present in the fluegas is roughly proportional to the oxygen concentration [29]. The situation with chlorine is more complex. Investigations by Wang et al [37] and Kanters et al[28] led to the approximation

$$
\begin{gathered}
{[\mathrm{PCP}]=0.01\left[\mathrm{O}_{2}\right][\mathrm{Cl}] \mu \mathrm{mol} \mathrm{Sm}^{-3} \quad 0<[\mathrm{Cl}]<0.7 \%} \\
{[\mathrm{PCP}]=0.007\left[\mathrm{O}_{2}\right] \mu \mathrm{mol} \mathrm{Sm}{ }^{-3} \quad[\mathrm{Cl}]>0.7 \% ; 0<\left[\mathrm{O}_{2}\right]<15}
\end{gathered}
$$

where $\left[\mathrm{O}_{2}\right]$ is the oxygen concentration as mass $\%$ in the combustion gas.

A consequence of this type of formulation is the response of the system to the nature of the time-temperature profile. If the temperature experienced by the reactants is constant, at low temperatures the formation rate exceeds the destruction rate, such that the concentration of PCDD/F increases indefinitely (subject to the availability of reactants). As time passes, the build-up of product continues to suffer decomposition, which results in a steady-state situation i.e. the concentration of PCDD/F no longer increases. An example of this effect is evident in Figure 1 for simulation of the experiment of Sidhu et al [6], where any experimental results are shown as a short line on the right-hand side. At higher temperatures steady-state is rapidly achieved: at $800^{\circ} \mathrm{C}$ the system achieves equilibrium after only $0.019 \mathrm{~s}$ in a total residence time of 2 seconds. This type of measured data is therefore not of instantaneous rates, but the product after a set time at specific conditions. 


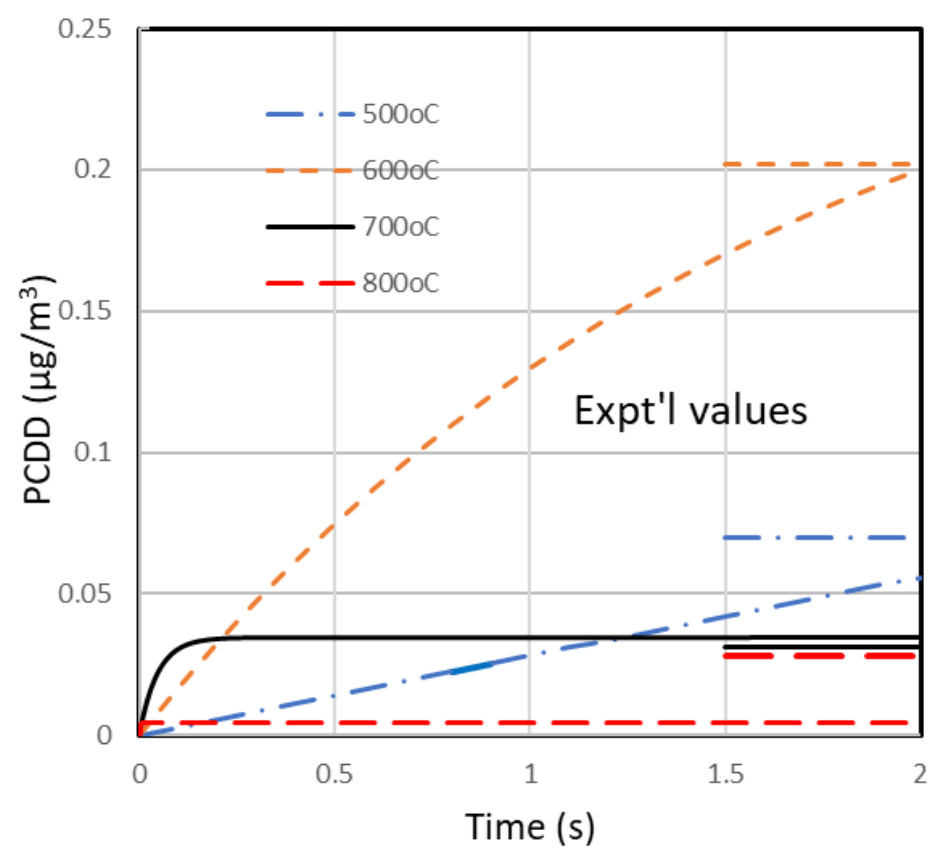

Figure 1 Simulation of gas phase dioxin formation from trichlorophenol.

A further complexity arises when the system is not isothermal, such as in the cooling of combustion gases leaving a furnace and passing through downstream equipment. If the temperature of a parcel of gas transporting ash is falling, the residual PCDD/F formed at higher temperatures experiences a lower rate of destruction than found in an isothermal system. With decreasing temperature, its concentration will increase at a faster rate. On the other hand, a rising temperature will tend to destroy more of this material, leading to a difference between the two configurations.

In a MSW furnace for example, rapid cooling is desirable. The effect is illustrated in Figure 2 for the $\mathrm{T}_{3} \mathrm{CP}$ initial experimental conditions of Sidhu. At a cooling rate of $250^{\circ} \mathrm{C}$ per second i.e. "rapid cool", the nett instantaneous rates of formation are higher at the top end temperatures than the original Sidhu data shown in Figure 1, with a maximum rate found at 650 rather than $600^{\circ} \mathrm{C}$. For "rapid heat" at $250^{\circ} \mathrm{C} \mathrm{s}^{-1}$, the result is similar to "rapid cool" at low temperatures, but any formation stops abruptly around $660^{\circ} \mathrm{C}$. The effects are intensified under "slow" conditions of $25^{\circ} \mathrm{C}$ per second, Figure 2. The usually quoted temperature "windows" are misleading. 


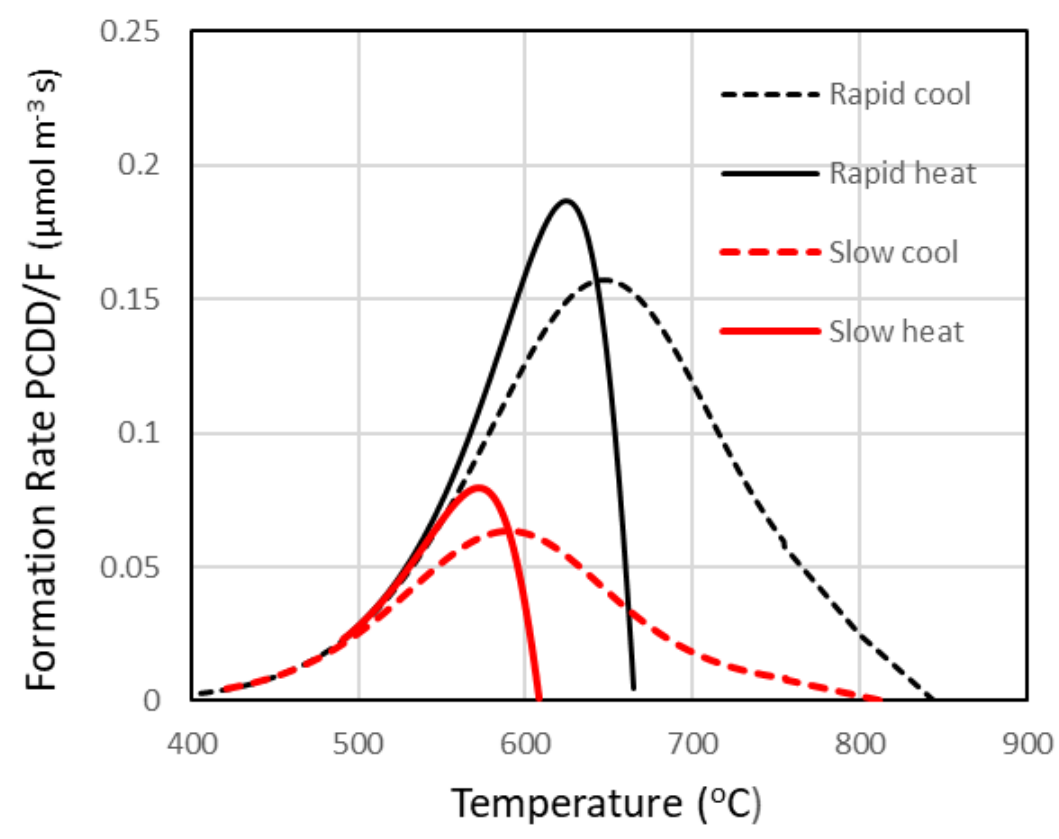

Figure 2 The effect of non-isothermal conditions on gas phase PCDD formation.

The lower rates experienced under slow cooling will not compensate for the extended period at elevated temperatures which the gases will experience. As the temperature falls from 850 to $400^{\circ} \mathrm{C}$, the "rapid" process in Figure 2 takes $1.8 \mathrm{~s}$ and forms $0.123 \mu \mathrm{mol} \mathrm{Sm}{ }^{-3}$ of PCDD/F, while the "slow" process takes $18 \mathrm{~s}$ and forms $0.438 \mu \mathrm{mol} \mathrm{Sm}{ }^{-3}$. The instantaneous generation rate (nett change) follows the left-hand (low temperature) arm of the nest of curves unless the destruction rate is significant.

\subsection{Surface Formation on the Solid Ash}

The surface of particulates is active in the formation of PCDD/F, affording sites for the adsorption/reaction of gas-phase molecules (precursor mode), and also allowing oxygen to attack native carbon to form organics such as $\mathrm{PAH}, \mathrm{PCP}, \mathrm{PCBz}$ and $\mathrm{PCDD} / \mathrm{F}$, the de novo reaction [38]. There appears to be a significant exchange of such compounds between the gaseous and solid phases. Much of the chlorocompounds found in the gas phase may originally have been formed on the particulates present, and subsequently devolatilised [39].

The BET surface area for carbon does not correlate with PCDD/F formation [40]. The use of external surface for analysis is also consistent with the results for MSW ash of Mätzing et al [39], who found that the global area was similar to the BET area, suggesting that the particles had negligible porosity, and only a few percent of the BET area was present as active sites [34].

In order to convert the results from a surface to a mass basis $\left(\mathrm{ng} \mathrm{g}^{-1} \mathrm{~s}^{-1}\right)$, the molecular mass of the PCDD/F and the specific surface area of the ash particles must be known. The average molecular mass of the product PCDD/F (MPCDD/F) can be taken as that of the hexachloro congeners i.e. $\sim 380 \mathrm{~g}$ $\mathrm{mol}^{-1}$ and surface area can be calculated for spherical particles by

$$
A_{s}=\frac{3}{d_{p}} m^{2} g^{-1}
$$


where $d_{p}$ is the mean particle diameter $(\mu \mathrm{m})$ and the ash density is assumed to be $2000 \mathrm{~kg} \mathrm{~m}^{-3}$. Then the mass rate is

$$
\frac{\mathrm{d}_{\mathrm{PCDD} / \mathrm{F}}}{\mathrm{dt}}=\mathrm{R}_{\mathrm{nett}} \mathrm{M}_{\mathrm{PCDD} / \mathrm{F}} \mathrm{A}_{\mathrm{s}} \quad \mathrm{ng} \mathrm{g}^{-1} \mathrm{~s}^{-1}
$$

The mass results can be converted to I-TEQ by dividing the calculated value by $\varphi$, the ratio of the $\mathrm{PCDD} / \mathrm{F}$ to the I-TEQ in the sample:

$$
[\mathrm{I}-\mathrm{TEQ}]=\frac{[\mathrm{PCDD} / \mathrm{F}]}{\varphi} \mathrm{ng}_{\mathrm{I}-\mathrm{TEQ}} \mathrm{g}^{-1} \mathrm{~s}^{-1}
$$

The value of $\varphi$ is the inverse of the effective toxicity factor for the sample. It is typically between 50 and 100 , i.e. the effective toxicity factor lies between 0.02 and 0.01 .

\subsubsection{Precursor PCDD/F}

The rate of formation is limited by the availability of precursor molecules in the gas phase, by their adsorption onto the solid surface, and by the need to react with a neighbour [17, 41]. To estimate formation rates, the work of Altwicker [10] with MSW flyash was used, affording the parameters for Equations (1D) and 1(E) of Table 1. No data suitable for estimating furan formation was found.

\subsubsection{De Novo PCDD/F}

A similar surface approach is used for the de novo reaction, with competition between formation and destruction, furnishing Equations (1F) and (1G). A solid-state reaction between carbon, oxygen and chlorine occurs during formation, with the rate of PCDD/F production determined by the rate of carbon oxidation [38]. This can be taken as constant with time, as was found during the annealing of four different MSW flyashes for $30 \mathrm{~min}$ at $300^{\circ} \mathrm{C}$ [42]. The order of reaction of carbon with respect to oxygen below $900^{\circ} \mathrm{C}$ is variable [43], but generally falls between 0.6 and unity. A value found for MSW ash is 0.54 [42], so that 0.6 was assumed.

Since the carbon $[\mathrm{C}]$ and chlorine contents $[\mathrm{Cl}]$ in the ash are of the first order with respect to PCDD/F product [24], these two elements as well as oxygen are taken as reactants. Some 30 minute annealing trials carried out by Altwicker on two MSW ashes with different carbon contents were the experimental bases for parameter fitting. While the chlorine contents of the two samples are not available, the values listed in the literature for MSW flyash range from 0.9 to $15 \%$ [44, 45]. The concentrations used for the two fly ashes were arbitrarily set at 3 and $4 \%$ respectively to fit the simulation.

Figure 3 depicts the results of the modelling, and the derived values are given as Equations (1F) and (1G) in Table 1. The oxygen concentration present when deriving (1F) was $10 \%$ by volume (which is almost the same by mass in flue-gases). The result can be converted into an I-TEQ mass basis using Equations (4), (5) and (6). 


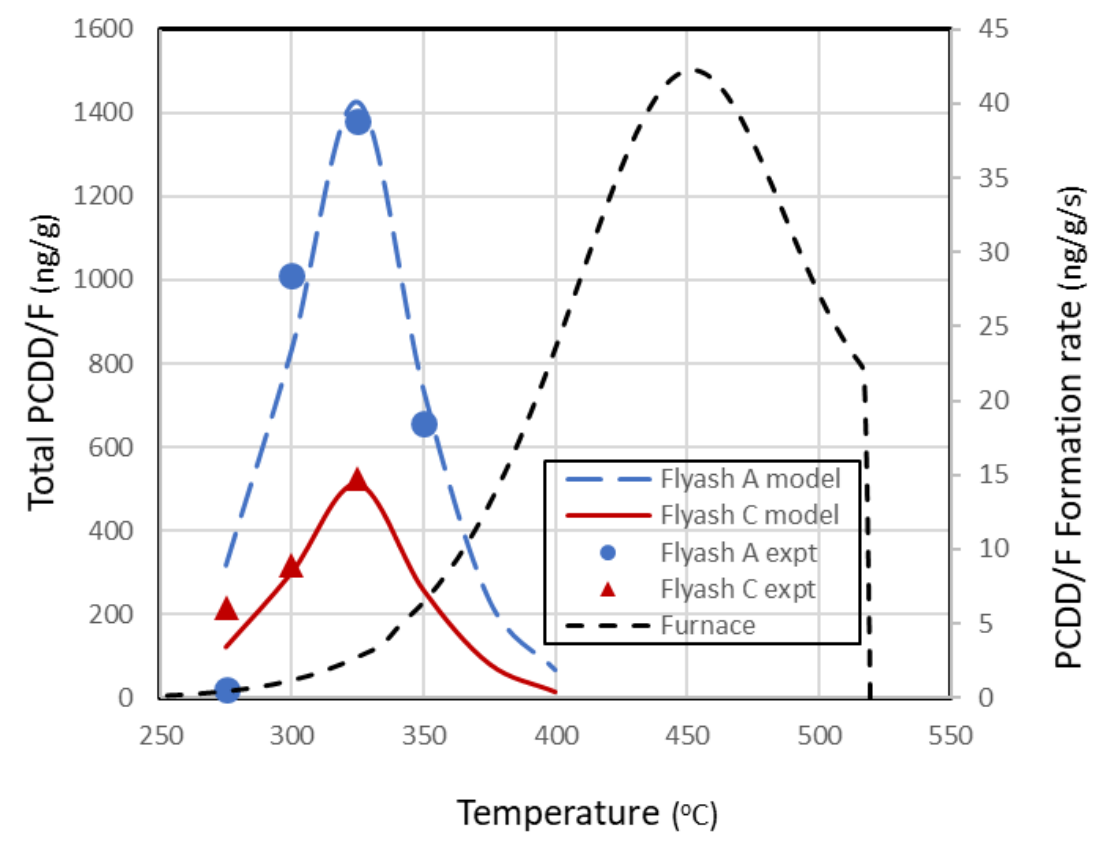

Figure 3 Simulation of de novo PCDD/F formation on MSW flyash.

Flyash is especially active in promoting PCDD/F formation, for two reasons - the small particle size, and the enrichment of chlorine [46]. It has been shown the reactions are concentrated on the particle surface i.e. the surface concentrations on MSW ash of dioxins/furans (ng m$~^{-2}$ ) are constant for all particle sizes under similar conditions of formation [24].

Wikstrom et al [47] concluded that ash-based chlorine was the dominant source under all conditions, and added chloride acted as a chlorinating agent only when no alternative chlorine was available [48]. Metals in the ash are known to be active in promoting the reactions, either by shuttling gaseous chlorine to the organic species as with copper [49], or by catalysis:

$$
2 \mathrm{CuCl}_{2}+\mathrm{R}-\mathrm{H} \rightarrow 2 \mathrm{CuCl}+\mathrm{R}-\mathrm{Cl}+\mathrm{HCl}
$$

The influence of copper in the ash was examined and found to promote the rate linearly with concentration [49]. Iron is active, but at a lower effectiveness [50, 51]. Water vapour also actively promotes PCDD/F formation on flyash [52]. In practical combustion situations, there is sufficient water to fully facilitate this process.

Another consideration for particulate formation is the action of sulphur in the system, which appears to inhibit the catalytic action of copper and other metals. The rate of de novo PCDD/F formation should be adjusted by a coefficient equal to $\exp \left(-0.0038 \mathrm{C}_{\mathrm{sO} 2}\right)$, where the sulphur dioxide concentration is in $\mathrm{mg} \mathrm{Sm}^{-3}$ [22].

The presence of metals in the ash catalyses the reaction via the rate of carbon oxidation [42], so that the type of metals in the source material will influence the result. In order to carry out a prediction, the nature of the parent fuel or a metal analysis would be helpful. Copper is by far the most active of the metals [53].

\section{Application of the Model}

Simulations involving the three completely different systems are now described. 


\subsection{Pilot Scale Fluidised Bed MSW Incinerator}

The $5 \mathrm{~kW}$ pilot scale incinerator at Umeå University in Sweden burns simulated MSW in a bubbling fluidised bed. There is a gas residence time in the bed/freeboard section of about $4 \mathrm{~s}$ at a temperature of $850^{\circ} \mathrm{C}$, falling over $4.5 \mathrm{~s}$ to $270^{\circ} \mathrm{C}$. The experimental data for the conditions examined here (Run 6 of [29]) include only the gas-phase results.

A simulation of the total system was carried out, using the measured concentrations of PCP. Figure 4 presents the results of the simulation, which includes the homogeneous and de novo mechanisms of PCDD/F formation, although measured results for the de novo route are unavailable. The concentrations of chlorophenols and chlorobenzenes in the gas phase were so low that precursor formation on the ash was negligible. PCDD and PCDF begin to appear in the gas phase of the bed around $720^{\circ} \mathrm{C}$ and plateau around $480^{\circ} \mathrm{C}$. The final concentrations are below those measured.

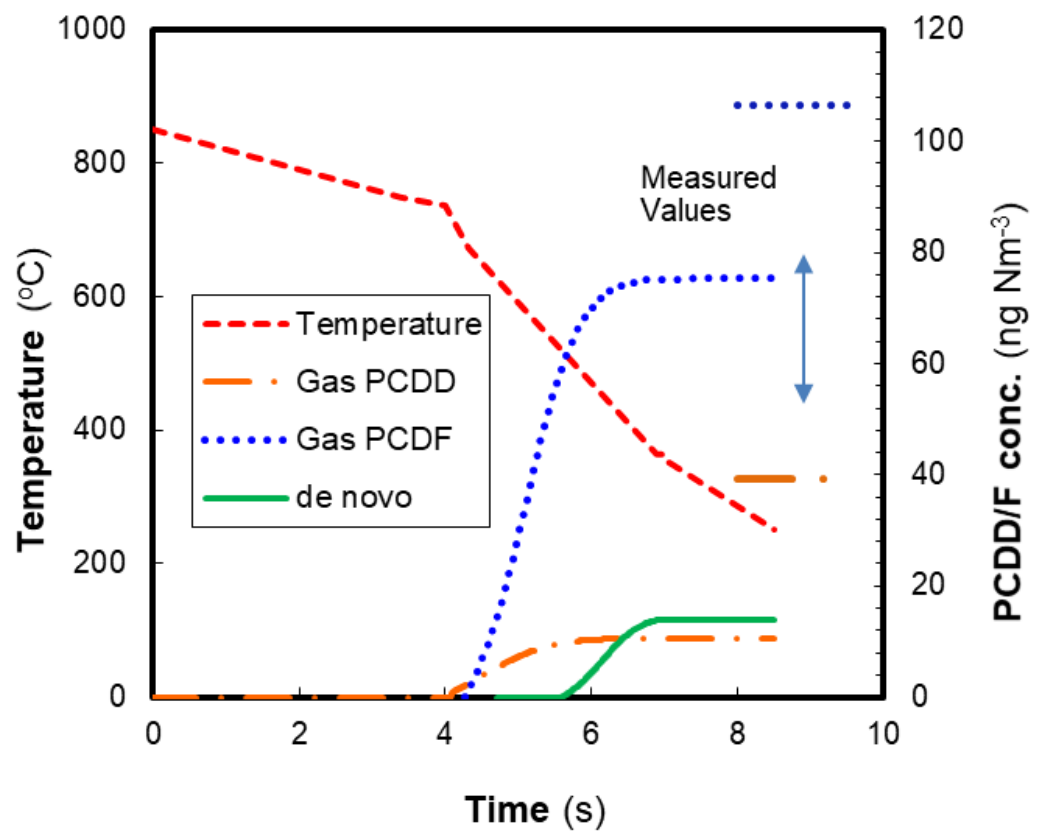

Figure 4 Simulation PCDD/F formation in the Umea furnace burning MSW.

The de novo estimation used $2 \%$ carbon and $1.9 \%$ chlorine, while $\mathrm{SO}_{2}$ concentration decreased de novo PCDD/F formation by $29 \%$. The high particulates burden of $850 \mathrm{mg} \mathrm{Sm}^{-3}$ and an assumed 100 micron mean particulate size led to $0.38 \mathrm{ngl-TEQ} \mathrm{g}^{-1}$ on the ash.

The de novo results for Run 6 were obtained at a cooling rate of $120^{\circ} \mathrm{C}$ per second from 600 to $360^{\circ} \mathrm{C}$, followed by $70^{\circ} \mathrm{C}$ per second below that temperature. They are superimposed on data of Figure 3, although the values for PCDD/F yield are arbitrary. The peak rate takes place at $450^{\circ} \mathrm{C}$ rather than at $325^{\circ} \mathrm{C}$. As in gas-phase processes, the generation curve lies at temperatures well above the "window" from which the kinetic parameters were derived. The upper-end discontinuity is due to the initial integration time step. 


\subsection{Commercial Fluidised Bed Wood-Fired Boiler}

Some emission data from a commercial bubbling fluidised bed boiler of nominal $70 \mathrm{MW}_{\mathrm{t}}$ capacity operated at a paper factory were obtained during commissioning tests (Casauria [54]). The fuel was a mixture of plantation off-cuts and recovered timber, which contained about $0.015 \%$ of chlorine on a dry mass basis, and the resulting bottom ash $0.15 \%$. It was necessary to estimate the flyash chlorine concentration, which was taken as $0.75 \%$.

The time-temperature and results are presented in Figure 5. Equation (2) was used to estimate the PCP, and PCBz was assumed to be the same. The flyash was $8.8 \mathrm{mg} \mathrm{Sm}^{-3}$ in the gas, with carbon assumed to be $2 \%$, and the mean particle size for wood-based flyash estimated from Lanzersdorfer was $4.3 \mu \mathrm{m}$. The de novo mechanism overwhelms the gas-phase emissions. The measured limit of detection values (LOD and half LoD) are also shown as short lines on the right-hand side.

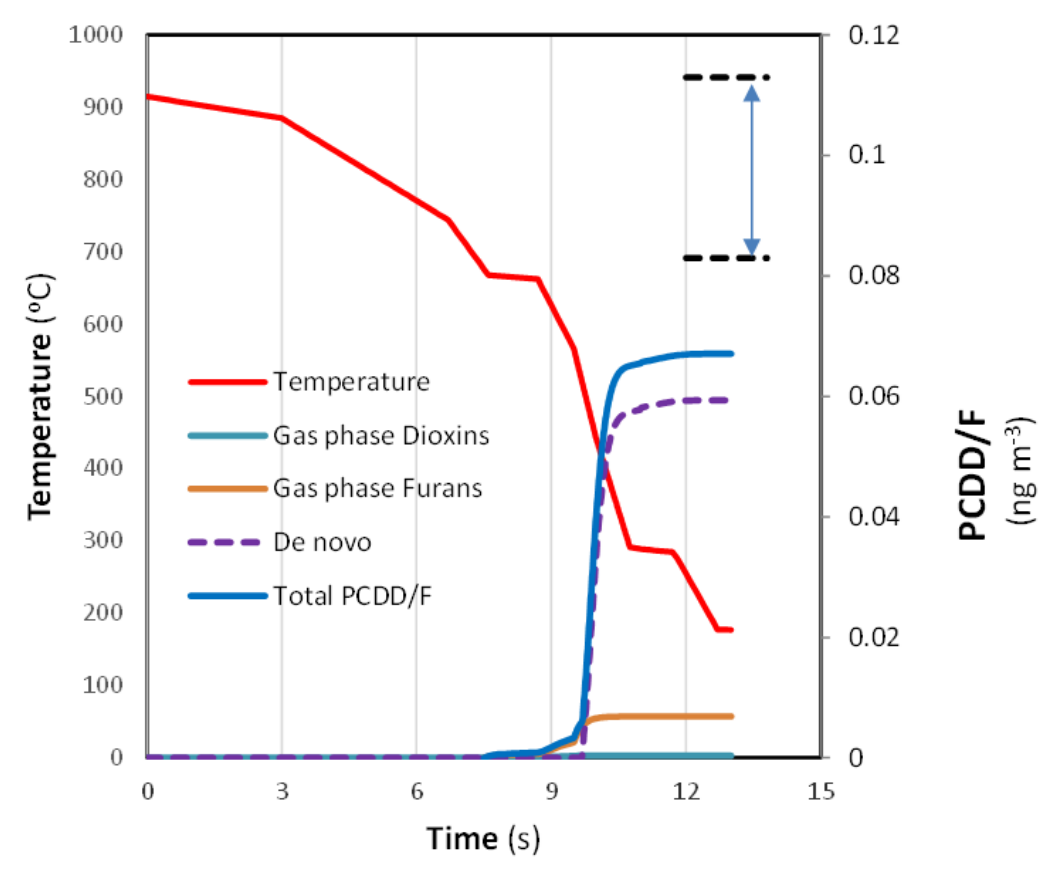

Figure 5 Simulation of PCDD/F formation in a wood-fired BFB furnace.

\subsection{Iron Ore Sinter Strand Particulates}

A flyash from iron ore sinter operations was annealed under air to establish its propensity to form PCDD/F [18]. A carbon content of $2.7 \%$ and chlorine of $9.55 \%$ were supplied; as $73 \%$ of the sample was less than 40 microns in size, the mean size was set at $20 \mu \mathrm{m}$. Equation (1F) predicted rates one to two orders of magnitude faster than the sinter ash, so the parameters were adjusted to fit, reflecting the predominance of iron. The activation energy for formation was increased, whereas that for destruction was reduced.

The result is Figure 6, where concentration ( $\mathrm{ng} \mathrm{g}^{-1}$ ) is plotted against annealing time (min), together with experimental values. At the low temperature of $250^{\circ} \mathrm{C}$, the plot is almost linear, as the destruction rates are negligible. At higher temperatures, the rates are higher but curvature appears as the rate of destruction on the surface rivals that of formation. Finally, around $325^{\circ} \mathrm{C}$ a maximum appears around $150 \mathrm{~min}$; but is less than the maxima which would be reached at lower temperatures. 


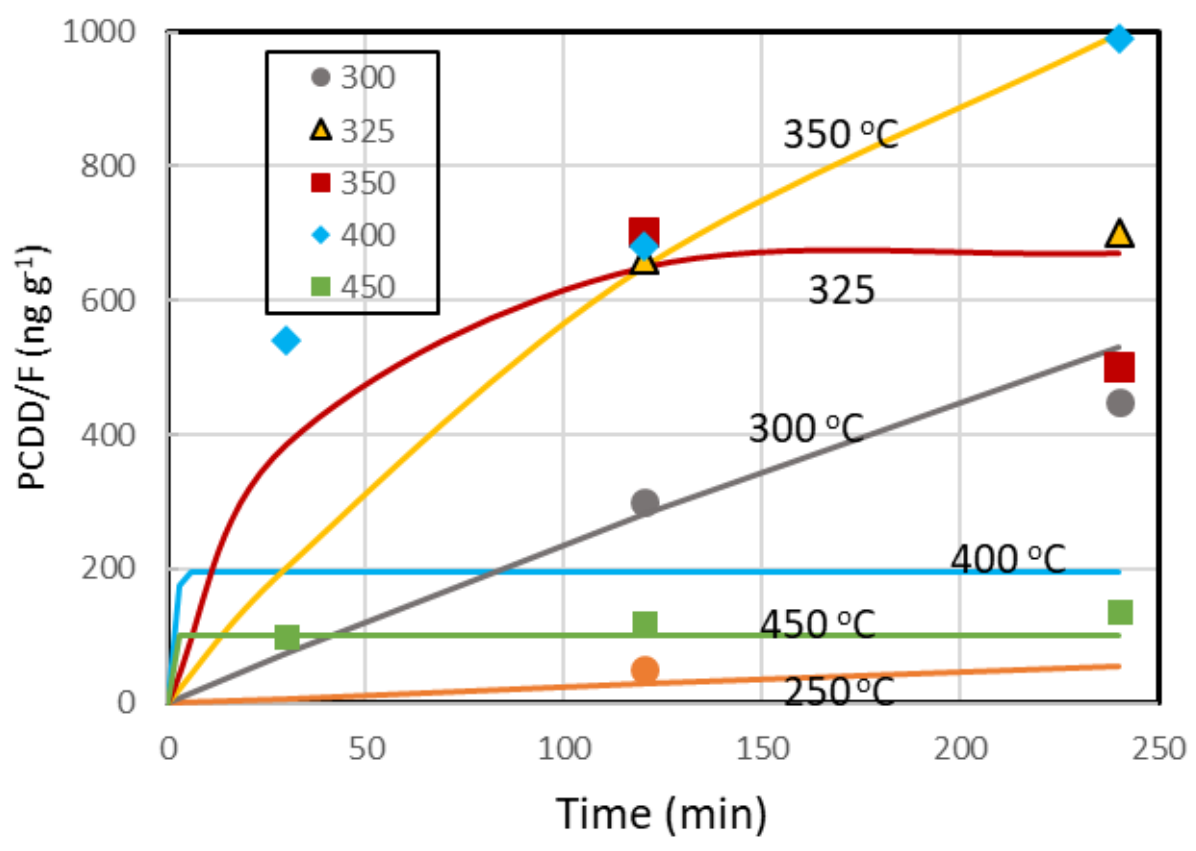

Figure 6 Simulation of de novo PCDD/F formation in iron sinter flyash.

At $350^{\circ} \mathrm{C}$ the trend in observed experimental behaviour is disturbed such that a plateau is not reached even after 2 hours. The higher temperatures evidently allow reaction to proceed inside the particle, possibly because the Tammann temperature of either chloride of any copper present is exceeded [24]. All the results except those for 350 and $400^{\circ} \mathrm{C}$ closely follow the trends and values measured experimentally.

\section{Conclusions}

Use of a two-process model for PCDD/F (formation /destruction) produces acceptable agreement during the simulation of three different thermal systems. The rapid cooling of flue-gases indicates that the maximum rate of PCDD/F formation in furnaces occurs at higher temperatures than found in isothermal laboratory tests. Better accuracy in prediction will be afforded when similar operations are considered viz MSW, biomass, iron sinter, etc. The precursor ash pathway is negligible under most conditions. There is a need for better characterisation of the ash, to include carbon, chlorine and copper concentrations, as well as particle size distribution.

\section{Author Contributions}

The author did all the research work of this study.

\section{Competing Interests}

The authors have declared that no competing interests exist. 


\section{References}

1. Altarawneh M, Dlugogorski BZ, Kennedy EM, Mackie JC. Mechanisms for formation, chlorination, dechlorination and destruction of polychlorinated dibenzo-p-dioxins and dibenzofurans (PCDD/Fs). Prog Energy Combust Sci. 2009; 35: 245-274.

2. Oh J-E, Touati A, Gullett BK, Mulholland JA. PCDD/F TEQ indicators and their mechanistic implications. Environ Sci Technol. 2004; 38: 4694-4700.

3. Shaub WM, Tsang W. Dioxin formation in incinerators. Environ Sci Technol. 1983; 17: 721-730.

4. Shaub WM, Tsang W. In Chlorinated dibenzodioxins and dibenzofurans in the total environment Choudhary. Oxford, UK: Butterworth-Heinemann; 1985. pp 469-487

5. Kaune A, Lenoir D, Nikolai U, Kettrup A. Estimating concentrations of polychlorinated dibenzop-dioxins and dibenzofurans in the stack gas of a hazardous waste incinerator from concentrations of chlorinated benzenes and biphenyls. Chemosphere. 1994; 29: 2083-2096.

6. Sidhu S, Maqsud L, Dellinger B, Mascolo G. The homogeneous, gas-phase formation of chlorinated and brominated dibenzo-p-dioxin from 2, 4, 6-trichloro-and 2, 4, 6-tribromophenols. Combust Flame. 1995; 100: 11-20.

7. Taylor PH, Sidhu SS, Rubey WA, Dellinger B, Wehrmeier A, Lenoir D, et al. Evidence for a unified pathway of dioxin formation from aliphatic hydrocarbons. Proc Combust Inst. 1998; 27: 17691775.

8. Milligan MS, Altwicker ER. Chlorophenol reactions on fly ash. 1. Adsorption/desorption equilibria and conversion to polychlorinated dibenzo-p-dioxins. Environ Sci Technol. 1995; 30: 225-229.

9. Penner S, Li C, Richards M, Wiesenhahn D. A model for de novo synthesis and decomposition rates of dioxins and furans in municipal waste incinerators. Sci Total Environ. 1991; 104: 35-46.

10. Altwicker ER. Formation of PCDDF in municipal solid waste incinerators: Laboratory and modeling studies. J Hazard Mater. 1996; 47: 137-161.

11. Babushok V, Tsang W. Gas-phase mechanism for dioxin formation. Chemosphere. 2003; 51: 1023-1029.

12. Khachatryan L, Asatryan R, Dellinger B. Development of expanded and core kinetic models for the gas phase formation of dioxins from chlorinated phenols. Chemosphere. 2003; 52: 695-708.

13. Gullett BK, Lemieux PM, Dunn JE. Role of combustion and sorbent parameters in prevention of polychlorinated dibenzo- $p$-dioxin and polychlorinated dibenzofuran formation during waste combustion. Environ Sci Technol. 1994; 28: 107-118.

14. Shin D, Choi S, Oh J-E, Chang Y-S. Evaluation of polychlorinated dibenzo- $p$-dioxin/dibenzofuran (PCDD/F) emission in municipal solid waste incinerators. Environ Sci Technol. 1999; 33: 26572666.

15. Chang NB, Chen W. Prediction of PCDDs/PCDFs emissions from municipal incinerators by genetic programming and neural network modeling. Waste Manag Res. 2000; 18: 341-351.

16. Chagger $\mathrm{H}$, Jones J, Pourkashanian $\mathrm{M}$, Williams $\mathrm{A}$. The formation of VOC, PAH and dioxins during incineration. Process Saf Environ Prot. 2000; 78: 53-59.

17. Huang $H$, Buekens $A$. Chemical kinetic modelling of PCDD formation from chlorophenol catalysed by incinerator fly ash. Chemosphere. 2000; 41: 943-951.

18. Xhrouet C, Pirard C, De Pauw E. De novo synthesis of polychlorinated dibenzo-p-dioxins and dibenzofurans on fly ash from a sintering process. Environ Sci Technol. 2001; 35: 1616-1623. 
19. Mätzing $H$. A simple kinetic model of PCDD/F formation by de novo synthesis. Chemosphere. 2001; 44: 1497-1503.

20. Gan S, Goh Y, Clarkson P, Parracho A, Nasserzadeh V, Swithenbank J. Post-combustion formation of dioxins/furans in waste incinerator plants. J Inst Energy. 2003; 76: 11-21.

21. Grandesso E, Ryan S, Gullett B, Touati A, Collina E, Lasagni M, et al. Kinetic modeling of polychlorinated dibenzo-p-dioxin and dibenzofuran formation based on carbon degradation reactions. Environ Sci Technol. 2008; 42: 7218-7224.

22. Stanmore B, Clunies-Ross $C$. An empirical model for the de novo formation of PCDD/F in medical waste incinerators. Environ Sci Technol. 2000; 34: 4538-4544.

23. Stanmore BR, Clunies-Ross C. Modeling the formation of PCDD/F in solid waste incinerators. $6^{\text {th }}$ Symposium on Combustion for a Clean Environment; 2001; Porto, Portugal.

24. Stanmore BR. Adsorption and partitioning of PCDD/F on flyash from incinerators. Environ Eng Sci. 2002; 19: 69-78.

25. Stanmore BR. Modeling the formation of PCDD/F in solid waste incinerators. Chemosphere. 2002; 47: 565-573.

26. lino F, Imagawa T, Takeuchi M, Sadakata M. De novo synthesis mechanism of polychlorinated dibenzofurans from polycyclic aromatic hydrocarbons and the characteristic isomers of polychlorinated naphthalenes. Environ Sci Technol. 1999; 33: 1038-1043.

27. Altwicker ER, Konduri RKN, Milligan M. The role of precursors in formation of polychlorodibenzo-p-dioxins and polychloro-dibenzofurans during heterogeneous combustion. Chemosphere. 1990; 20: 1935-1944.

28. Kanters $M$, Van Nispen $R$, Louw R, Mulder P. Chlorine input and chlorophenol emission in the lab-scale combustion of municipal solid waste. Environ Sci Technol. 1996; 30: 2121-2126.

29. Wikström E, Tysklind M, Marklund S. Influence of variation in combustion conditions on the primary formation of chlorinated organic micropollutants during municipal solid waste combustion. Environ Sci Technol. 1999; 33: 4263-4269.

30. Oh J-E, Gullett B, Ryan S, Touati A. Mechanistic relationships among PCDDs/Fs, PCNs, PAHs, ClPhs, and ClBzs in municipal waste incineration. Environ Sci Technol. 2007; 41: 4705-4710.

31. Scholz M, Stieglitz L, Will R, Zwick G. The formation of $P C B$ on fly ash and conversion to PCDD/PCDF. Organohal Compd. 1997; 31: 538-541.

32. Stieglitz L, Bautz $H$, Roth W, Zwick G. Investigation of precursor reactions in the de-novosynthesis of PCDD/PCDF on fly ash. Chemosphere. 1997; 34: 1083-1090.

33. Cieplik MK, De Jong V, Bozovič J, Liljelind P, Marklund S, Louw R. Formation of dioxins from combustion micropollutants over MSWI fly ash. Environ Sci Technol. 2006; 40: 1263-1269.

34. Collina E, Lasagni M, Pitea D, Keil B, Stieglitz L. Degradation of octachlorodibenzofuran and octachlorodibenzo-p-dioxin spiked on fly ash: Kinetics and mechanism. Environ Sci Technol. 1995; 29: 577-585.

35. Jay K, Stieglitz L. Identification and quantification of volatile organic components in emissions of waste incineration plants. Chemosphere. 1995; 30: 1249-1260.

36. Wilken M, Böske J, Jager J, Zeschmar-Lahl B. PCDD/F, PCB, chlorobenzene and chlorophenol emissions of a Municipal Solid Waste Incineration plant (MSWI) - variation within a five day routine performance and influence of $\mathrm{Mg}(\mathrm{OH})$ 2-addition. Chemosphere. 1994; 29: 2039-2050. 
37. Wang LC, Lee WJ, Lee WS, Chang-Chien GP, Tsai PJ. Effect of chlorine content in feeding wastes of incineration on the emission of polychlorinated dibenzo-p-dioxins/dibenzofurans. Sci Total Environ. 2003; 302: 185-198.

38. Lasagni M, Collina E, Grandesso E, Piccinelli E, Pitea D. Kinetics of carbon degradation and PCDD/PCDF formation on MSWI fly ash. Chemosphere. 2009; 74: 377-383.

39. Mätzing H, Baumann W, Becker B, Jay K, Paur HR, Seifert H. Adsorption of PCDD/F on MWI fly ash. Chemosphere. 2001; 42: 803-809.

40. Stieglitz L, Zwick G, Beck J, Bautz H, Roth W. The role of particulate carbon in the de-novo synthesis of polychlorinated dibenzodioxins and-furans in fly-ash. Chemosphere. 1990; 20: 1953-1958.

41. Hell K, Stieglitz L, Altwicker E, Addink R, Will R. Reactions of 2, 4, 6-trichlorophenol on model fly ash: Oxidation to $\mathrm{CO}$ and $\mathrm{CO}_{2}$, condensation to PCDD/F and conversion into related compounds. Chemosphere. 2001; 42: 697-702.

42. Milligan MS, Altwicker E. The catalytic gasification of carbon in incinerator fly ash. Carbon. 1993; 31: 977-986.

43. Hurt RH, Calo JM. Semi-global intrinsic kinetics for char combustion modeling. Combust Flame. 2001; 125: 1138-1149.

44. Cains PW, McCausland L, Fernandes AR, Dyke P. Polychlorinated dibenzo- $p$-dioxins and dibenzofurans formation in incineration: Effects of fly ash and carbon source. Environ Sci Technol. 1997; 31: 776-785.

45. Takasuga T, Makino T, Tsubota K, Takeda N. Formation of dioxins (PCDDs/PCDFs) by dioxin-free fly ash as a catalyst and relation with several chlorine-sources. Chemosphere. 2000; 40: 10031007.

46. Buekens A, Stieglitz L, Hell K, Huang H, Segers P. Dioxins from thermal and metallurgical processes: Recent studies for the iron and steel industry. Chemosphere. 2001; 42: 729-735.

47. Wikström E, Ryan S, Touati A, Telfer M, Tabor D, Gullett BK. Importance of chlorine speciation on de novo formation of polychlorinated dibenzo-p-dioxins and polychlorinated dibenzofurans. Environ Sci Technol. 2003; 37: 1108-1113.

48. Addink R, Espourteille F, Altwicker ER. Role of inorganic chlorine in the formation of polychlorinated dibenzo- $p$-dioxins/dibenzofurans from residual carbon on incinerator fly ash. Environ Sci Technol. 1998; 32: 3356-3359.

49. Weber P, Dinjus E, Stieglitz L. The role of copper (II) chloride in the formation of organic chlorine in fly ash. Chemosphere. 2001; 42: 579-582.

50. Ryan SP, Altwicker ER. The formation of polychlorinated dibenzo- $p$-dioxins/dibenzofurans from carbon model mixtures containing ferrous chloride. Chemosphere. 2000; 40: 1009-1014.

51. Liao J, Buekens A, Olie K, Yang J, Chen T, Li X. Iron and copper catalysis of PCDD/F formation. Environ Sci Pollut Res. 2016; 23: 2415-2425.

52. Briois C, Ryan S, Tabor D, Touati A, Gullett BK. Formation of polychlorinated dibenzo-p-dioxins and dibenzofurans from a mixture of chlorophenols over fly ash: Influence of water vapor. Environ Sci Technol. 2007; 41: 850-856.

53. Vogg H, Metzger M, Stieglitz L. Recent findings on the formation and decomposition of PCDD/PCDF in municipal solid waste incineration. Waste Manag Res. 1987; 5: 285-294.

54. Casauria B. personal communication. 


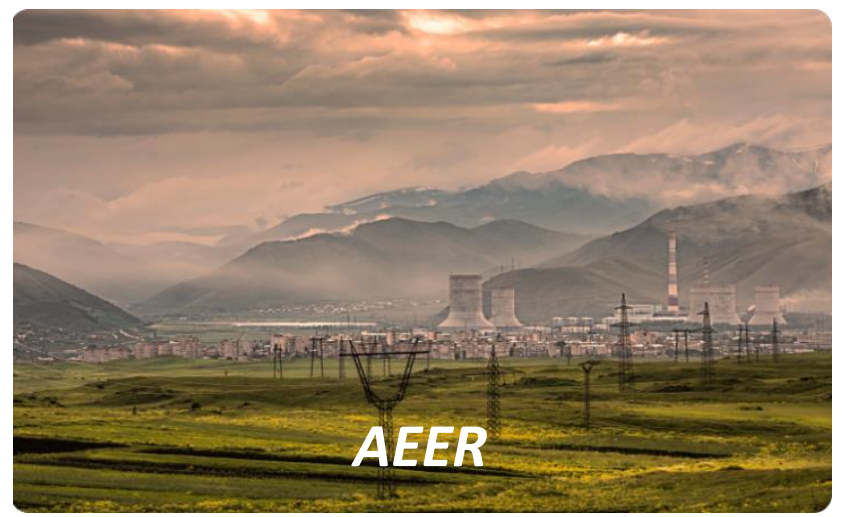

Enjoy $A E E R$ by:

1. Submitting a manuscript

2. Joining in volunteer reviewer bank

3. Joining Editorial Board

4. Guest editing a special issue

For more details, please visit:

http://www.lidsen.com/journals/aeer 